\title{
FLEXURE OF A FLOATING ICE TONGUE*
}

\author{
By G. Holdsworth ${ }^{\dagger}$ \\ (Institute of Polar Studies, Ohio State University, Columbus, Ohio 432 ro, U.S.A.)
}

\begin{abstract}
Several analyses are given for the flexure of a floating polar ice tongue with the general dimensions of several kilometers wide by $200 \mathrm{~m}$ in thickness. The lengths considered are from $2 \mathrm{~km}$ to in excess of $10 \mathrm{~km}$ which is referred to as a long slab. The analyses are made under the separate assumptions that ice behaves as (I) an elastic material, (2) an elastic-plastic material, and (3) a fully plastic material, when reacting to flexure due to changes in sea-level. The elastic analysis shows that hinge-line stresses could become very high (of the order of ${ }_{5} 5$ bar) for slab lengths up to about $3.5 \mathrm{~km}$ reacting to sea-level changes of the order of $+50 \mathrm{~cm}$. For slab lengths greater than this, the stresses at the hinge, as well as being significantly less than before, become independent of the length of the slab, dependent only on the slab thickness and the amount of deflection of sea-level. In the elastic-plastic analysis, the hinge-line stress cannot exceed a value of about 2 bar. This yield value is reached when sea-level departs about $50 \mathrm{~cm}$ from the mean. The fully plastic analysis requires more accurate knowledge of the constants in the flow law and their variation with density, temperature and salinity within the ice. However, the theory may be tested by measuring the diurnal change in strain-rate across the hinge-line zone. The process of calving of large tabular icebergs from such glacier tongues may demand sea-level changes of more than $\pm 1 \mathrm{~m}$, or bending about more than one axis of the shelf.
\end{abstract}

Résumé. Flexion d'une langue glaciaire flottante. On donne pour la flexion d'une langue glaciaire polaire plusieurs analyses avec les dimensions générales de plusieurs kilomètres de large et $200 \mathrm{~m}$ d'épaisseur. Les longueurs considérées sont de $2 \mathrm{~km}$ à $\mathrm{ro} \mathrm{km}$ ce que l'on considère comme une longue plaque. Les analyses sont faites sous les hypothèses diverses que la glace se comporte comme une matière élastique (I), une matière plastique-élastique (2), et une matière plastique (3) lorsqu'elle réagit à la flexion due aux variations du niveau de la mer. L'analyse élastique montre que les contraintes à la ligne de flexion peuvent s'élever considérablement (de l'ordre de $\mathrm{I}_{5}$ bar) pour des longueurs de plaque allant jusqu'à $3,5 \mathrm{~km}$ réagissant à la variation du niveau de la mer de $50 \mathrm{~cm}$. Pour des plaques plus grandes, les contraintes à la ligne de flexion, même si elles sont plus faibles, deviennent indépendantes de la longueur de la plaque et dependant seulement de l'épaisseur et de la variation du niveau de la mer. Dans l'analyse plastique-élastique, la contrainte à la ligne de flexion ne peut dépasser une valeur de 2 bar. Cette valeur d'élongation est atteinte lorsque le niveau de la mer s'écarte de $5^{\circ} \mathrm{cm}$ du niveau moyen. L'analyse entièrement plastique demande plus de connaissance précise quant aux constantes des lois d'écoulement et leurs variations avec la densité, la température et la salinité de la glace. Cependant la théorie peut être testée en mesurant la variation diurne de la vitesse de déformation à travers la zone de ligne de flexion.

Zusammenfassung. Biegung einer schwimmenden Eiszunge. Für die Biegung (Flexur) einer schwimmenden Polareiszunge von einigen Kilometern Breite und $200 \mathrm{~m}$ Dicke werden verschiedene Analysen angestellt. Die Länge der Zunge wird von $2 \mathrm{~km}$ bis über $10 \mathrm{~km}$ variiert, womit sich der Fall einer langen Platte ergibt. Die Analysen werden unter den getrennten Annahmen durchgeführt, dass sich Eis bei Biegung infolge von Meeresspiegelschwankungen verhält wie (I) ein elastisches, (2) ein elastisch-plastisches und (3) ein rein plastisches Material. Die Elastizitätsanalyse zeigt, dass für Platten bis zu $3,5 \mathrm{~km}$ Länge bei der Reaktion auf Meeresspiegelschwankungen von $\pm 50 \mathrm{~cm}$ die Spannung an der Auflagelinie sehr hoch werden kann (in der Grössenordnung von 15 bar). Bei längeren Platten wird die Spannung am Auf lager bedeutend geringer als zuvor und unabhängig von der Plattenlänge; sie bleibt abhängig nur von der Plattendicke und dem Ausmass der Meeresspiegeländerung. Bei der Analyse als elastisch-plastisches Material kann die Spannung an der Auflagelinie einen Wert von etwa 2 bar nicht überschreiten. Dieser Höchstwert wird bei Abweichungen des Meeresspiegels um etwa $50 \mathrm{~cm}$ vom Mittel erreicht. Die Analyse als rein plastisches Material erfordert eine genauere Kenntnis der Konstanten des Fliessgesetzes und ihrer Veränderung mit Dichte, Temperatur und Salzgehalt des Eises. Die Theorie kann jedoch durch Messung der täglichen Änderung der Dehnungsgeschwindigkeit innerhalb der Zone längs der Auflagelinie geprüft werden.

\section{List of Symbols Used}

$x, y, z$ coordinate axes; $x$ longitudinal, $y$ transverse, $z$ vertical (Fig. 4).

$\sigma_{i j} \quad i, j=x, y, z ; i=j$ : normal stress. $i \neq j$ : shear stress.

$\sigma_{i j}^{\prime} \quad$ stress deviator.

$\sigma_{x x}(z)$ normal stress in the $x$ direction, at distance $z$ from the neutral axis.

$\sigma_{0 x}(-h)$ normal stress in the $x$ direction at $x=0$, on the surface of the slab.

$\dot{\epsilon}_{i j} \quad i, j=x, y, z ;$ strain-rate.

* Contribution No. 122, Institute of Polar Studies, Ohio State University, Columbus, Ohio, U.S.A.

$\uparrow$ Present address: Inland Waters Branch, Department of Energy, Mines and Resources, Ottawa, Ontario, Canada. 
$\dot{\epsilon}_{x x}(z) \quad$ strain-rate in the $x$ direction at $z$ from the neutral axis.

$w^{\prime \prime}(x) \quad$ curvature of the neutral axis, in the $x z$ plane at a distance $x$ from the origin.

$w^{\prime}(x)$ slope of the neutral axis, in the $x z$ plane at a distance $x$ from the origin.

$w(x)$ vertical deflection of the neutral axis at a distance $x$ from the origin.

$w_{\mathrm{a}}$ vertical deflection of the neutral axis as $x$ tends to large values - see text.

$w_{\mathrm{s}}$ depression or elevation of sea-level from mean sea-level.

$\rho_{\mathrm{w}}$ density of sea-water. $1.028 \mathrm{Mg} \mathrm{m}^{-3}$.

$\tilde{\rho}_{\mathrm{i}} \quad$ mean density of the ice slab $=\int_{-h}^{h} \rho_{\mathrm{i}}(z) \mathrm{d} z / 2 h$.

e exponential factor.

$\lambda$ damping factor per unit distance.

$g$ acceleration due to gravity. $9.8 \mathrm{I} \mathrm{m} \mathrm{s}^{-2}$.

$h$ half thickness of the ice slab. ( $h$ is taken as roo $\mathrm{m}$ in all calculations.)

$K$ yield stress in pure shear for elastic-plastic analysis. Value taken as $\mathrm{I}$ bar $=\mathrm{IO}^{5}$ $\mathrm{N} \mathrm{m}^{-2}$ (see Nye, I95I).

$L$ length of ice slab when not semi-infinite.

$E_{\mathrm{b}}$ Young's modulus of ice in bending (see Tabata, r967, p. 493).

$I_{\mathrm{a}}$ second moment of area of the section $\left(=\frac{2}{3} h^{3}\right)$ per unit width.

$\mu$ Poisson's ratio for ice, taken as 0.3 (Dorsey, 1940).

$M(x)$ bending moment at a section distance $x$ from the origin.

$x^{\star}$ distance from the origin to point where the plastic region disappears (elastic-plastic analysis only).

$\xi$ distance from the neutral axis to elastic-plastic boundary.

$n$ exponent in the power flow law for ice (for calculations $n$ is taken as 3 ).

$A$ constant in the flow law (steady-state creep) but strongly dependent on temperature, density, etc.

$t$ time.

- dot over a symbol denotes differentiation with respect to time.

\section{Introduction}

Surrounding the Antarctic continent are several large ice shelves, many smaller ice shelves and floating ice tongues. It is from these features that most icebergs are generated. With increasing activity in the polar regions within the last decade, it has become necessary to understand better the mechanical behavior of a floating ice mass because:

(I) scientific bases have been constructed on them,

(2) shipping lanes in these waters are often governed by the presence of enormous tabular icebergs which calve off from the shelves periodically, and

(3) certain hypotheses (viz. Wilson, 1964) concerning the dynamics of continental ice sheets feeding such shelves, demand a knowledge of the subsequent behavior of the floating ice masses once they have been formed.

Figure I shows three relatively small ice tongues. The Erebus Glacier Tongue (a) on Ross Island is known, from gravimeter measurements (Holdsworth, unpublished data in I966) to be oscillating as far inland as approximately the section $\mathrm{yy}^{\prime}$. From altimetry the central ice thickness is estimated as being up to $200 \mathrm{~m}$, assuming a mean ice density of $0.88 \mathrm{Mg} \mathrm{m}^{-3}$. The width is 1.5 to $2 \mathrm{~km}$ and the length $8.5 \mathrm{~km}$.

The Suvorov Ice Tongue (Oates Coast), Figure I(b), is substantially larger, and unlike the Erebus Glacier Tongue, its length is about equal to its width, assuming a hinge line in the position marked. It is particularly amenable, therefore, to the kind of analysis which follows, under the specific set of assumptions that are made. 


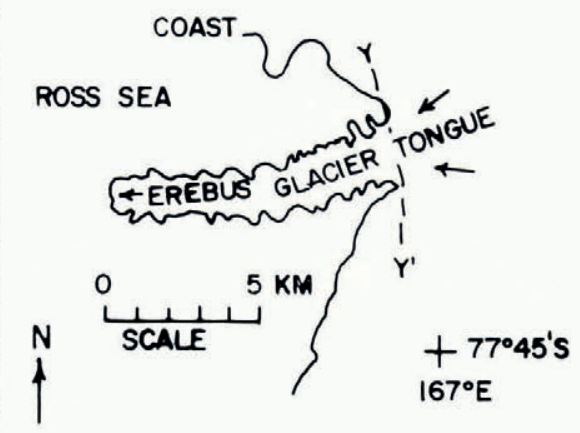

(a) EREBUS GLACIER TONGUE
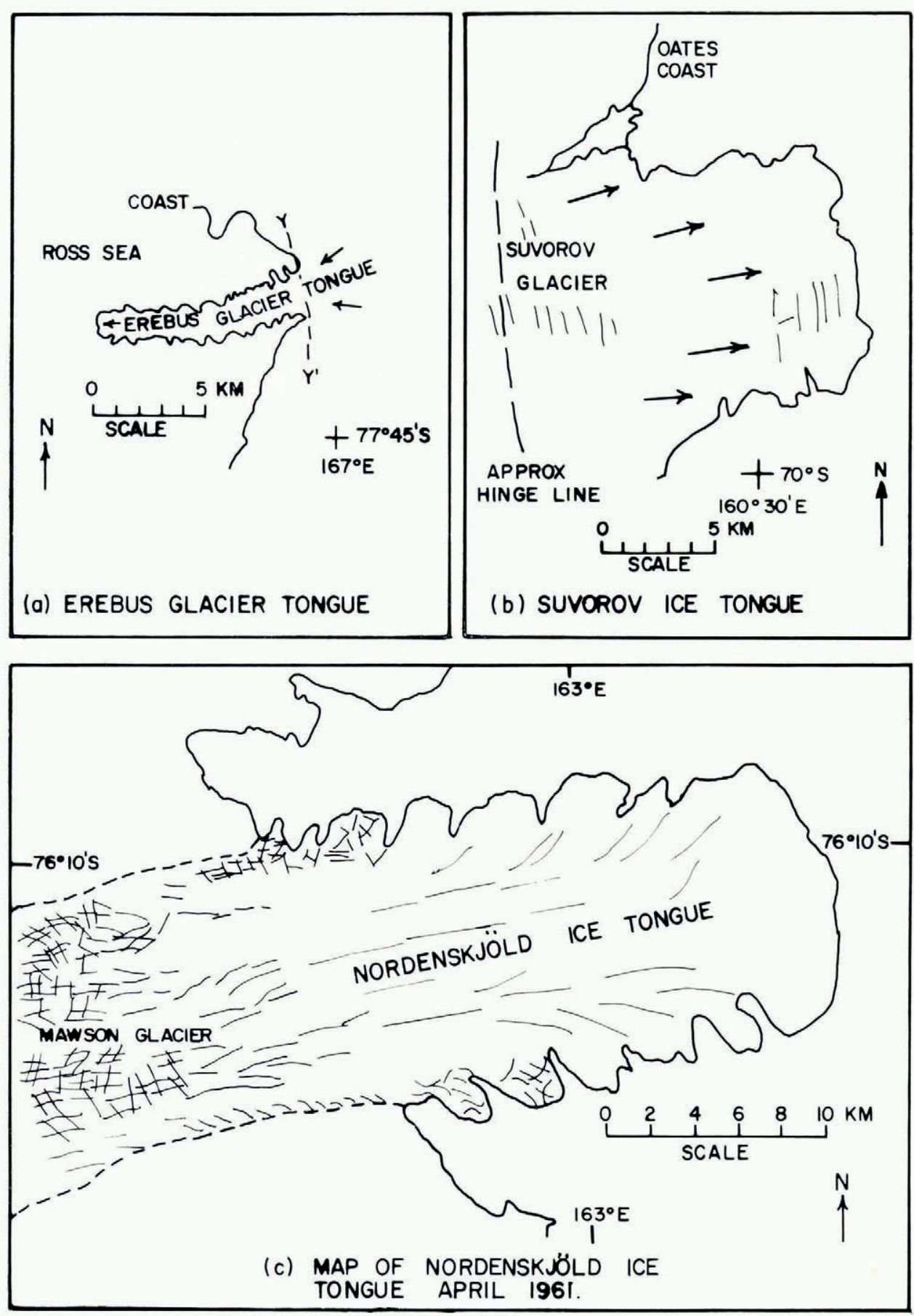

Fig. I. Floating ice tongues in Antarctica. 
In recent years the positions of the ice fronts have been mapped by the U.S. Coast Guard icebreakers, and it has subsequently been deduced that sections, if not all, of a particular ice tongue have broken off at some time within a known year (for example, the Nordenskjöld Ice Tongue (Fig. I (c)) probably broke off some time in 1964).

\section{Deflection of a Floating Ice Mass}

Several components are involved in producing the vertical oscillation of a floating ice tongue (or a major ice shelf), namely, oscillations due to:

(I) wave motion (small amplitude of slab movement in millimeters; short period, generally less than $\mathrm{I}$ min, e.g. Erebus Glacier Tongue, $\approx \mathrm{r} 6 \mathrm{~s}$ );

(2) diurnal tidal motion (medium amplitude, I to $3 \mathrm{~m}$, period $\mathrm{I} 2$ to $24 \mathrm{~h}$, see Thiel and others, I96o);

(3) astronomical tides of medium to large amplitude, with periods from several weeks to I9 years. Included here are the well known "spring tides" (Stewart, [1963]);

(4) catastrophic impulses, e.g. tsunamis, earthquakes, violent storms, abnormal ocean currents, etc.;

(5) miscellaneous influences, e.g. differential changes in atmospheric pressure over the shelf surface, differential accumulation or ablation on the surface of the shelf, forced wind oscillations, all of which are probably insignificant compared with the preceding influences.

One method of detecting vertical displacements of an ice shelf at any point, has been described by Weinman (1958) and Thiel and others (r96o).

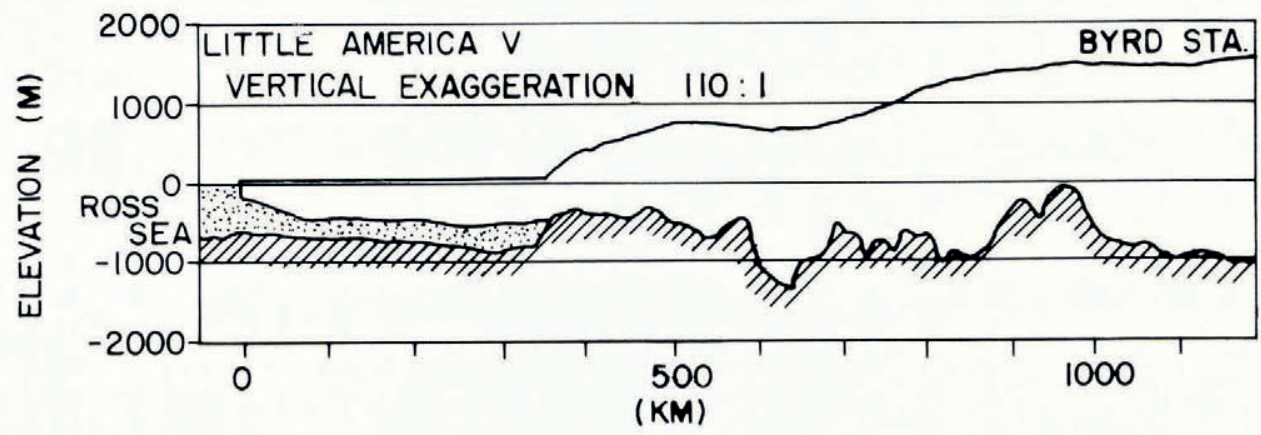

Fig. 2. Profile of ice thickness of part of the Ross Ice Shelf, Antarctica, after Thiel and Ostenso (1961, p. 824).

\section{The Problem}

From the foregoing discussion and consideration of Figure 2, which is taken from Thiel and Ostenso (196I), it is apparent that the system being studied might be represented by a simplified model, to be discussed in detail later. Certain assumptions are made, viz.:

(I) The width $y$ is considered to be much greater than the thickness $2 h$ of the slab which is of length $L$ measured horizontally from the effective hinge $(x=0)$. The order of magnitude of $L$ is discussed later. A "long" or semi-infinite slab is considered to be one exceeding about $4 \mathrm{~km}$ in length with an average thickness of $200 \mathrm{~m}$. Plane strain conditions are assumed to exist and beam theory is used for simplicity of analysis. However, for very wide tongues (where $L$ is also large), secondary bending in the $y z$ plane may become significant. In the present analysis this will be neglected. 
(2) For large values of $x$ the ice mass may be treated as a freely floating slab of uniform thickness and density, responding to changes in sea-level. If $h=h(x)$ is known then this could be used, but it greatly increases the difficulty of solution of the differential equations. Similarly the assumption of uniform density simplifies the solution.

(3) The horizontal displacement of the slab is neglected; i.e. the slab is assumed constant in length over the period of time involved in a cycle of flexure.

(4) Inertia effects are neglected, as all vertical movements are relatively slow. The problem is treated as one in statics.

(5) The bending effect produced by the imbalance of ice pressure and hydrostatic pressure at the immediate ice front, as well as at the edges of an unconfined slab, is a local (though very significant) effect (Reeh, I968), but it is the concern of this paper to investigate the bending in the much larger zone from the hinge line to within a few hundred meters from the terminal cliff and lateral margins. Thus the edge boundary condition of hydrostatic pressure is avoided.

According to Reeh's analysis, icebergs produced by his mechanism would tend to be strongly prismatic, whereas many of the Antarctic icebergs are strongly tabular with both horizontal dimensions measured in kilometers or tens of kilometers, and with thicknesses of 200 to $400 \mathrm{~m}$. Consequently it is evidently necessary to investigate the stresses due to bending along the entire length of the slab. It may also be noted that Reeh (1968, p. 225-26) has provided time estimates for his proposed calving mechanism. These indicate that, for typical Antarctic ice masses, a deflection rate at the edge, of about $2 \mathrm{~mm}$ per $\mathrm{I} 2 \mathrm{~h}$ period is likely to occur (assuming ice to have a constant viscosity). This is seen to be very small compared with the tidal ( 6 to $12 \mathrm{~h}$ ) deflections of several meters, with which this analysis is primarily concerned.

The flexural analysis will be considered separately according to elastic-plastic and steadystate creep theories. It will be tacitly assumed that the bending function moment $M(x)$ for a long ice slab has the same form in all cases. Plastic deformation due to bending is presumed to be of the same order of magnitude as a corresponding elastic deformation, because of the cyclical variation from tensile to compressive strains.

Finally, it is to be expected that the shorter the period of oscillation of the slab, the more the response would tend to be an elastic one (see section 2(I) and (2)).

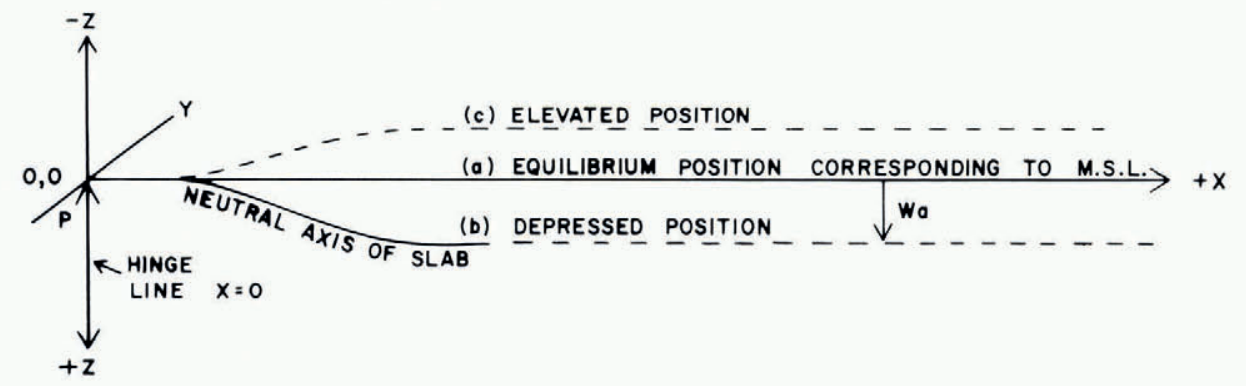

Fig. 3. Hetényi model (vertical scale exaggerated).

\section{Elastic Analysis}

It is necessary now to discuss in detail, the model used for the present analysis. For this it is convenient to use the analogue of the system in which a semi-infinite elastic beam, resting on a horizontal elastic foundation, is depressed at its center by a point load. This classical problem has been solved by Hetényi (1946). By inverting this system, eliminating the half to the left of the center of symmetry, and shifting the origin to the neutral axis of the slab in the line of the point load, a model, which will be called the Hetényi model, is formed (Fig. 3), in which 
for large values of $x$ the deflection tends to a constant value along the slab. The unbent position corresponds to mean sea-level. Consider first a depression of sea-level. It is assumed that at large values of $x$ the ice is freely floating, thus $w=w_{\mathrm{a}}=w_{\mathrm{s}}$. In accordance with the assumptions made by Hetényi, for the foundation reaction, it will be initially assumed here that the distributed load acting vertically downward on the displaced parts of the slab, is directly proportional to the vertical distance $w_{\mathrm{a}}-w(x)$ (Fig. 4). This turns out to be correct because the ice in this region remains above its equilibrium floating position for the new sealevel, corresponding to (b) in Figure 4, and the downward-acting distributed load acting on a strip of width $\mathrm{d} x$ at distance $x$ from the origin, is exactly $\rho_{\mathrm{w}} g\left(w_{\mathrm{a}}-w(x)\right) \mathrm{d} x$.

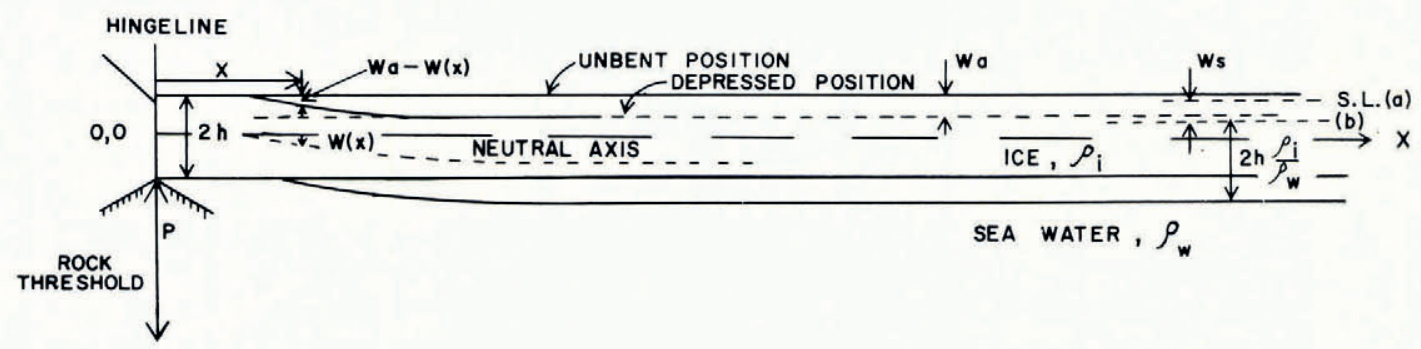

Fig. 4. Model ice tongue (developed from the Hetényi model), distorted vertical scale.

The force $P$ acting upward at the origin may be identified with the "reaction" or vertical shear force at the hinge.

Considering inertial effects of this system to be minimal it is sufficient to treat the problem as one in statics. Starting from the well known equation for a beam in bending,

$$
w^{\prime \prime}(x)=-\frac{\left(\mathrm{I}-\mu^{2}\right)}{E_{\mathrm{b}} I_{\mathrm{a}}} M(x),
$$

where $M(x)$ is the bending moment at $x, E_{\mathrm{b}}$ is Young's modulus in bending, $I_{\mathrm{a}}$ is the moment of inertia of the section per unit width, and $\mu$ is Poisson's ratio, it may be shown that

$$
w^{\prime \prime \prime \prime}(x)=-\frac{\left(\mathrm{I}-\mu^{2}\right)}{E_{\mathrm{b}} I_{\mathrm{a}}} \rho_{\mathrm{w}} g\left(w_{\mathrm{a}}-w(x)\right)
$$

for the present problem. The solution turns out to be:

where

$$
\begin{aligned}
w(x) & =w_{\mathrm{a}}\left(\mathrm{I}-\mathrm{e}^{-\lambda x}(\cos \lambda x+\sin \lambda x)\right) \\
\lambda^{4} & =\frac{\rho_{\mathrm{w}} g\left(\mathrm{I}-\mu^{2}\right)}{4 E_{\mathrm{b}} I_{\mathrm{a}}} .
\end{aligned}
$$

$\lambda$ is known as the damping factor. The significant quantity is $I / \lambda$, whose value in the present case is approximately $900 \mathrm{~m}$, taking the following values: $\rho_{\mathrm{w}}=1.028 \mathrm{Mg} \mathrm{m}^{-3}, \mu=0.3$, $E_{\mathrm{b}}=2.7 \times \mathrm{IO}^{4}$ bar (Dorsey, I940, p. 445; Tabata, I967, p. 493), $I_{\mathrm{a}}=\frac{2}{3} h^{3}$ where $h=\mathrm{I} 00 \mathrm{~m}$.

The specified boundary conditions for Equation (4.2) are

$$
\begin{array}{rlrl}
w(0) & =0, \quad w(x \rightarrow \infty) & =z_{\mathrm{a}}, \\
w^{\prime}(0) & =0, \quad w^{\prime}(x \rightarrow \infty)=0 .
\end{array}
$$

$w(x)$ has the value $w_{\mathrm{a}}$ when $x=\frac{3 \pi}{4 \lambda}, \frac{7 \pi}{4 \lambda}, \frac{\mathrm{I} \mathrm{I} \pi}{4 \lambda}, \ldots, \frac{(4 n-\mathrm{I}) \pi}{4 \lambda}$.

Between these points the deflection curve follows a flat wave trajectory of decreasing amplitude with distance $x$. 
Differentiating Equation (4.2) twice,

$$
\begin{aligned}
w^{\prime}(x) & =2 w_{\mathrm{a}} \lambda \mathrm{e}^{-\lambda x} \sin \lambda x, \\
w^{\prime \prime}(x) & =2 w_{\mathrm{a}} \lambda^{2} \mathrm{e}^{-\lambda x}(\cos \lambda x-\sin \lambda x),
\end{aligned}
$$

and using Equation (4.0),

$$
M(x)=-\frac{\rho_{\mathrm{w}} g w_{\mathrm{a}}}{2 \lambda^{2}} \mathrm{e}^{-\lambda x}(\cos \lambda x-\sin \lambda x),
$$

$M(x)=\mathrm{o}$, when $x=\frac{\pi}{4 \lambda}, \frac{5^{\pi}}{4 \lambda}, \frac{9^{\pi}}{4 \lambda}, \ldots, \frac{\left(4^{n-3}\right) \pi}{4 \lambda}$.

Of greatest interest is the stress $\sigma_{x x}$ generated at the hinge-line position $(x=0)$. The maximum tensile stress produced by a downward deflection $+w_{\mathrm{a}}$ will obviously occur at the surface $z=-h$. Using beam theory and Equation (4.6)

$$
\sigma_{x x}(-h)=+\frac{\rho_{\mathrm{w}} g h w_{\mathrm{a}}}{2 I_{\mathrm{a}} \lambda^{2}} \mathrm{e}^{-\lambda x}(\cos \lambda x-\sin \lambda x),
$$

$\sigma_{x x}(-h)=$ o when $x=\frac{\pi}{4 \lambda}, \frac{5 \pi}{4 \lambda}, \ldots, \frac{\left(4^{n-3}\right) \pi}{4^{\lambda}}$.

Now $\sigma_{0 x}(-h)=+\frac{\rho_{\mathrm{w}} g h w_{\mathrm{a}}}{2 I_{\mathrm{a}} \lambda^{2}}$ where the positive sign denotes tension. If the previously used values of $\rho_{\mathrm{w}}, h, I_{\mathrm{a}}$ and $\lambda$ are used, this reduces to

$$
\sigma_{0 x}(-h)=6.7 \times \mathrm{IO}^{-2} w_{\mathrm{a}} \text { bar. }
$$

For a downward deflection of $+50 \mathrm{~cm}$ the surface stress is about

$$
+3 \cdot 3 \text { bar. }
$$

At values of $x=0, \frac{\pi}{2 \lambda}, \frac{3 \pi}{2 \lambda}, \ldots, \frac{(2 n-\mathrm{I}) \pi}{2 \lambda},\left|\sigma_{x x}(-h)\right|$ maximizes, alternating between tension and compression along the slab surface.

The case where the slab is elevated above the mean position is taken to be the mirror image of the depressed case, assuming that the ice at the hinge does not lift off the bottom, a situation requiring the basal ice to be resting on a sharp rise or rock threshold, or where the thickness of the ice necks down rapidly to the hinge (Fig. 2). Thus, if $w(x \rightarrow \infty)=-w_{\mathbf{a}}$, the signs of the stress at these points are all reversed. The stresses at $\pi / 2 \lambda$ and $3 \pi / 2 \lambda$ are respectively less than $\pm \mathrm{I}$ bar and \pm o. $\mathrm{I}$ bar for $w_{\mathrm{a}}= \pm 50 \mathrm{~cm}$. Equation (4.7) gives values of bending stresses on the surface of the slab produced by various values of $w_{\mathrm{a}}$. If fracture is to occur it will first be manifest at the hinge line, then at a distance of approximately $\mathrm{I} .4 \mathrm{~km}$ from the hinge line.

At this point it would be convenient to investigate the effect of the length of the slab on the bending behavior. So far, only long slabs have been considered, i.e. where $L \gg 5 \pi / 4 \lambda$, or about $3.5 \mathrm{~km}$. "Intermediate length" slabs, where $L \approx 4 \mathrm{~km}$, could also be treated in a similar way to a first approximation, but for short slabs where $L<c .3 .5 \mathrm{~km}$, the problem will have to be treated somewhat differently.

Assume that the deflection curve of the top surface is parallel to the deflection curve of the neutral axis. Suppose that sea-level is depressed an amount $w_{\mathrm{s}}$ but that the end of the slab deflects only $w_{L}$. The necessary condition is that $w_{L} \leqslant w_{\mathrm{S}}$.

In the absence of prior knowledge about the form of the deflection curve, ultimately to be derived, the approximation is now made that the distributed load due to ice above its equilibrium position varies linearly along the slab, from $\rho_{\mathrm{w}} g w_{\mathrm{S}} \mathrm{d} x$ to $\rho_{\mathrm{w}} g\left(w_{\mathrm{s}}-w_{L}\right) \mathrm{d} x$ at the end. This is not such a severe assumption if $w_{L}$ is small compared with $L$ which is the condition of the present case. Consequently the bending moment at any point $x$ is given by

$$
M(x)=\frac{1}{6} \rho_{\mathrm{w}} g(L-x)^{2}\left(3 w_{\mathrm{S}}-2 w_{L}-w(x)\right) .
$$


Using Equations (4.0) and (4.8),

where

$$
\begin{gathered}
w^{\prime \prime}(x)=\alpha(L-x)^{2}(\beta-w(x)), \\
\alpha=-\frac{\rho_{\mathrm{W}}\left(\mathrm{I}-\mu^{2}\right) g}{4 E h^{3}}, \quad \beta=3 w_{\mathrm{S}}-2 w_{L} .
\end{gathered}
$$

The boundary conditions for Equation (4.9) are

A solution of this equation is

$$
w(\mathbf{0})=w^{\prime}(\mathbf{0})=0 .
$$

$$
w(x)=\beta+A(L-x) \sum_{k=0}^{\infty} \frac{(-\mathrm{I})^{k}\left[\frac{1}{2}(-\alpha)^{\mathrm{I} / 2}(L-x)\right]^{4 k}}{k ! \Gamma k+\frac{5}{4}}+B \sum_{k=0}^{\infty} \frac{(-\mathrm{I})^{k}\left[\frac{1}{2}(-\alpha)^{\mathrm{I} / 2}(L-x)\right]^{4 k}}{k ! \Gamma k+\frac{3}{4}}
$$

where the constants may be found from the boundary conditions.

Without some simplification this equation turns out to be very ponderous and will not be pursued, except to mention that the initial approximation is justified by it. What is more important to the present problem is the dependence of the hinge-line stress on the length of the slab and the end deflection.

Using Equations (4.0) and (4.9), in which $x=0, w(0)=0$ and the relationship $\sigma_{0} x(-h)=M(\mathrm{o}) h / I_{\mathrm{a}}$, it may be shown that:

$$
\sigma_{0} x(-h)=\frac{\rho_{\mathrm{w}} g}{4^{h^{2}}}\left(3 w_{\mathrm{s}}-2 w_{L}\right) L^{2}
$$

where the limits of $L$ are approximately given by

$$
0<L \leqslant 3.5 \mathrm{~km} \text {. }
$$

If the limiting case $w_{L}=w_{\mathrm{s}}$ is taken, Equation (4.10) may be rewritten

$$
\sigma_{\mathrm{o} x}(-h)=w_{\mathrm{s}} L^{2} c
$$

where $c$ has the value $0.25 \mathrm{I} \mathrm{N} \mathrm{m}^{-5}$.

For $w_{\mathrm{s}}= \pm 50 \mathrm{~cm}$ and $L=3.5 \mathrm{~km}$, the hinge stress is \pm 15.4 bars, which is of the order of the bending strength of ice at about $-20^{\circ} \mathrm{C}$ with a density above $0.85 \mathrm{Mg} \mathrm{m}^{-3}$ (Tabata, I 967 , p. 488-89). For values of $L$ greater than this, but leaving $w_{\mathrm{s}}$ unchanged, there is, according to this composite analysis, a reduction of the hinge stress to about $\frac{1}{5}$ of its maximum value.

Due to surface hinge-line stresses of several bars indicated in the case of an elastic slab (eliminating temporarily the horizontal steady-state creep, which is always tensile) it might be supposed that this is the region where plastic yield due to bending only would be likely to occur first. Consequently it is thought appropriate to present an elastic-plastic analysis of the same problem.

\section{Elastic-plastic Analysis}

Again, only flexure in the $x z$ plane of the slab is admitted. The stresses considered are the result of the bending moment only. The other component of stress in the $x$ direction is Weertman's steady-state creep stress (Weertman, 1957) which can only be tensile in the upper layers.

All the assumptions of sections 3 and 4 are again made. Further it is assumed that the bending contributes nothing to $\sigma_{z z}, \sigma_{x y}$ and $\sigma_{y z}$. Consequently the only non-vanishing stresses produced by bending are $\sigma_{x x}, \sigma_{y y}$ and $\sigma_{x z}$.

The stress deviators are

$$
\sigma_{i j}^{\prime}=\sigma_{i j}-\frac{1}{3} \delta_{i j} \sigma_{k k} \quad \text { where } \delta_{i j}= \begin{cases}\mathrm{o}, & i \neq j \\ \mathrm{I}, & i=j\end{cases}
$$


and $\sigma_{k k}=\sum \sigma_{i j}, i=j$, hence

$$
\begin{aligned}
\sigma_{x x}^{\prime} & =\frac{2}{3} \sigma_{x x}-\frac{1}{3} \sigma_{y y}, \\
\sigma_{y y}^{\prime} & =\frac{2}{3} \sigma_{y y}-\frac{1}{3} \sigma_{x x}, \\
\sigma_{z z}^{\prime} & =\frac{1}{3} \sigma_{x x}-\frac{1}{3} \sigma_{y y} .
\end{aligned}
$$

But for plane strain $\sigma_{y y}^{\prime}$ must be zero, therefore:

$$
\left|\sigma_{x x}\right|=2\left|\sigma_{y y}\right| \text {. }
$$

Using the von Mises yield criterion:

$$
\frac{1}{2}\left(\sigma_{x x}^{\prime 2}+\sigma_{y y}^{\prime 2}+\sigma_{z z}^{\prime 2}\right)+\sigma_{x y}^{2}+\sigma_{y z}^{2}+\sigma_{z x}^{2}=k^{2}
$$

where $k$ is the yield stress in pure shear, the relationship

$$
\sigma_{x x}^{2}+4 \sigma_{x z}^{2}=4^{2}
$$

is obtained. It may be shown (Prager and Hodge, I95 I, p. 44-53) that within the framework of beam theory $\sigma_{x z} \ll \sigma_{x x}$ and in the plastic regions $\sigma_{x z}$ actually vanishes. Indeed on the upper and lower surface $\sigma_{x z}=0$, always. Accordingly the yield condition may be sufficiently written:

$$
\left|\sigma_{x x}\right|=2 k \text {. }
$$

If the vertical displacement $w(x) \ll 2 h$ and the usual assumptions of the bending of beams are adopted then to a reasonable approximation

$$
\left(\mathrm{I}-\mu^{2}\right) \sigma_{x x}=-E_{\mathrm{b}} z w^{\prime \prime}(x)
$$

at all points where the material behaves elastically.

If the section in Figure 5 is considered, then the upper plastic region is specified by $\xi \leqslant z \leqslant h$, the elastic region by $-\xi \leqslant z \leqslant \xi$, and the lower plastic region by $-h \leqslant z \leqslant-\xi$, then the stresses in these regions are respectively

$$
\begin{aligned}
& \sigma_{x x}=2 k \quad \text { (tension if clockwise bending moment), } \\
& \sigma_{x x}=2 k z / \xi
\end{aligned}
$$

and $\quad \sigma_{x x}=-2 k$ when the yield stress has been reached in the outer parts of the section.
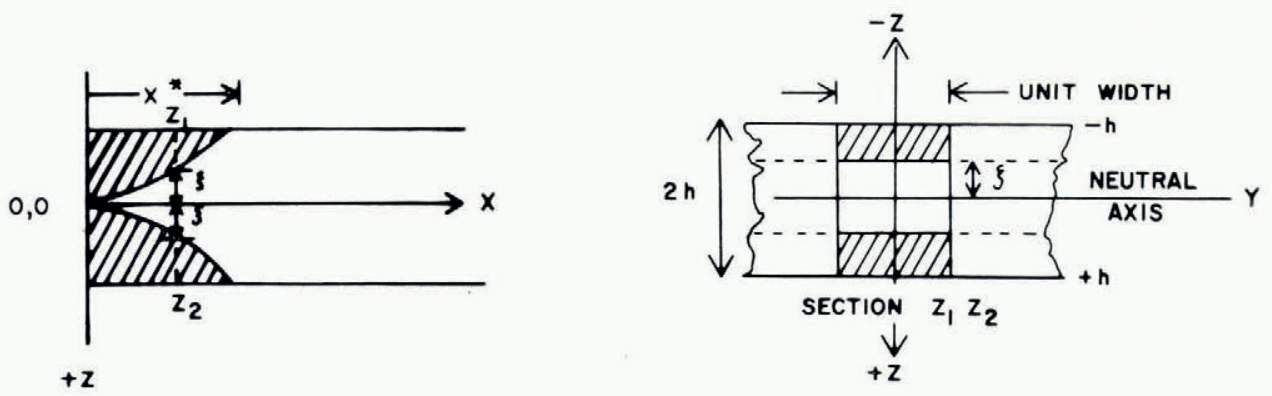

Fig. 5. Elastic-plastic regions of the slab at the hinge region, for a fully plastic section $x=0$. The bending moment $M(x)=2 \int_{0}^{h} \sigma_{x x}(z) z \mathrm{~d} z$ bearing in mind that the stresses due
to bending only are considered.

For an elastic section

$$
\begin{gathered}
M(x)=-\frac{2 E_{\mathrm{b}} h^{3} w^{\prime \prime}(x)}{3\left(\mathrm{I}-\mu^{2}\right)} . \\
M(x)=2 k\left(h^{2}-\frac{1}{3} \xi^{2}\right) . \\
M(x)=2 k h^{2} .
\end{gathered}
$$


Assuming that $M(x)$ takes the same form for all sections as discussed earlier, the form of Equation (4.6) will be used, namely:

$$
M(x)=M(\mathrm{o}) \mathrm{e}^{-\lambda x}(\cos \lambda x-\sin \lambda x) .
$$

The solution of Equation $(5 \cdot 3)$ has already been worked out in section 4 .

For the elastic-plastic section, from Equation (5. I):

$$
w^{\prime \prime}(x)=\frac{2 k\left(\mathrm{I}-\mu^{2}\right)}{E_{\mathrm{b}} \xi} .
$$

Equating Equation (5.4) with Equation (5.6), and using this last expression, the curvature becomes:

$$
w^{\prime \prime}(x)=\frac{2 k\left(\mathrm{I}-\mu^{2}\right)}{E_{\mathrm{b}}}\left[3 h^{2}-\frac{3 M(\mathrm{o})}{2 k} \mathrm{e}^{-\lambda x}(\cos \lambda x-\sin \lambda x)\right]^{-1 / 2} .
$$

The deflection curve is given by

$$
w(x)=\int_{0}^{x} \int_{0}^{x} \frac{2 k\left(\mathrm{I}-\mu^{2}\right)}{\sqrt{ } 3 E_{\mathrm{b}} h}\left[\mathrm{I}-\frac{M(\mathrm{o})}{2 k h^{2}} \mathrm{e}^{-\lambda x}(\cos \lambda x-\sin \lambda x)\right]^{-\mathrm{I} / 2} \mathrm{~d} x \mathrm{~d} x
$$

under the boundary conditions $w(0)=w^{\prime}(0)=0$.

The solution to Equation (5.8) can be rewritten in the form

$$
w(x)=A x^{2} \int_{0}^{1} \frac{(\mathrm{I}-\tau) \cdot \mathrm{d} \tau}{\left[\mathrm{I}-\alpha \mathrm{e}^{-\lambda x \tau}(\cos \lambda x \tau-\sin \lambda x \tau)\right]^{\mathrm{I} / 2}}
$$

where $A=2 k / \sqrt{ } 3 E_{\mathrm{b}} h$ and $\alpha=M(\mathrm{o}) / 2 k h^{2} . \quad \tau$ is a dummy variable. This curve is valid only over a distance $0 \leqslant x \leqslant x^{\star}$, where $x^{\star}$ is a solution of the equation

$$
3\left(\cos \lambda x^{\star}-\sin \lambda x^{\star}\right)=2 \exp \left(\lambda x^{\star}\right) .
$$

The value of $x^{\star} \approx \pi / \mathrm{I} 6 \lambda \approx \mathrm{I} 80 \mathrm{~m}$, or approximately the thickness of the slab, so for practical purposes Equation (5.8) or its equivalent is of little use.

Of specific interest is the stress generated at the hinge, which by hypothesis cannot be greater than $|2 k|$ or about 2 bar. This corresponds to a bending moment of $2 k h^{2}$ at an approximate value of $w_{\mathrm{a}} \approx \frac{4 k h^{2} \lambda^{2}}{\rho_{\mathrm{w}} g} \approx 49 \mathrm{~cm}$. This is then equivalent to a full tidal range of about I m, which is about the average for the Ross Sea (Thiel and others, I960, p. 633).

\section{Steady-state Creep Analysis}

An analysis based on creep bending requires a number of severe assumptions in addition to those already outlined in section 3. These are that:

(I) Plane sections remain approximately planar after flexure and the strain-rate $\dot{\epsilon}_{x x}$ is proportional to the distance $z$ from the neutral axis, which is assumed to be at mid-thickness of the slab (due to temperature and density variations with depth it is bound to be slightly displaced).

(2) An average flow law can be assigned to the full section to take account of varying density and temperature of the ice with depth.

(3) The steady-state creep law holds for both tension and compression induced by the influence of bending.

(4) The stresses due to bending are cyclical and may be analysed separately from those due to other causes.

Using assumption $(\mathrm{I}) \quad \dot{\epsilon}_{x x}(z) \approx \dot{\epsilon}_{x x}(h) z / h$. 
Using assumptions (2) and (3) the steady-state creep law may be written

$$
\left|\dot{\epsilon}_{x x}(z)\right|=A\left|\sigma_{x x}(z)\right|^{n}
$$

therefore

$$
M(x)=\frac{2 n h^{2}}{2 n+\mathrm{I}}\left|\frac{h}{z}\right|^{\mathrm{I} / n} \sigma_{x x}(z) .
$$

Assuming small displacements:

$$
\frac{\mathrm{d}\left(w^{\prime \prime}(x)\right)}{\mathrm{d} t}=\frac{\dot{\epsilon}_{x x}(h)}{h}=\frac{A}{h}\left(\frac{2 n+\mathrm{I}}{2 n h^{2}}\right)^{n} M(x)^{n} .
$$

For simplicity of analysis the bending moment will be assumed to be a function of the rate of deflection but not of the actual time. Thus if the rate of deflection is assumed roughly constant, the right-hand side of Equation (6.4) can be assumed to be independent of time, so

$$
w^{\prime \prime}(x)=\phi \mathrm{e}^{-3 \lambda x}(\cos \lambda x-\sin \lambda x)^{3}
$$

where $n$ has been put equal to 3 (Glen, i955, p. 528-29) and

$$
\phi=\phi(t, M(\mathrm{o}))=\frac{A t}{h^{7}}\left(\frac{7}{6}\right)^{3} M(\mathrm{o})^{3} .
$$

In solving Equation (6.5) it must be realized that although the resulting deflection $w(x)$ turns out to be an increasing function of time as well as $x$, it has to have very definite limits which are in this case controlled by sea-level.

The boundary conditions that must be satisfied are:

$$
w(0)=0 \quad \text { and } \quad w^{\prime}(\infty)=0,
$$

which enable a complete solution for Equation (6.5) to be written

$$
w(x)=-\frac{A}{\mathrm{I}_{5}{ }^{\mathrm{o} \lambda^{2} h^{7}}}\left(\frac{7}{6}\right)^{3} \frac{w_{\mathrm{a}}}{\dot{w}_{\mathrm{a}}} M(\mathrm{o})^{3}\left[3-\mathrm{e}^{-3 \lambda x}(3 \cos \lambda x+29 \sin \lambda x)\right] .
$$

This equation gives the deflection curve for given values of $w_{\mathrm{a}}$ and $\dot{w}_{\mathrm{a}}$ at the far end of the slab.

If $\dot{w}_{\mathrm{s}}$ is the rate of change of sea-level and $\dot{w}_{\mathrm{a}}$ is the rate of vertical movement of the slab for large $x$, then if $\dot{w}_{\mathrm{s}} \gg \dot{w}_{\mathrm{a}}$ the movement of the slab would lag behind the sea-level change. On the other hand, if $\dot{w}_{\mathrm{s}} \ngtr \dot{w}_{\mathrm{a}}$ then the deflection rate of the slab can only be exactly equal to $\dot{w}_{\mathrm{s}}$. This last case is the one considered to apply to diurnal tidal movements.

$$
\text { Placing } \quad w(\infty)=w_{\mathrm{a}}, \quad 0 \leqslant w_{\mathrm{a}}=w_{\mathrm{s}} \leqslant W_{\mathrm{s}}
$$

where $W_{\mathrm{s}}$ is the full departure of sea-level from mean sea-level it may be shown that:

$$
M(\mathrm{o})=3 \cdot 4^{2} h^{7 / 3} \lambda^{2 / 3} A^{-1 / 3} \dot{w}_{\mathrm{a}}{ }^{1 / 3}
$$

The value of $M(\mathrm{o})$ is thus dependent on $\dot{w}_{\mathrm{a}}$ but is rather insensitive to changes in this quantity.

Suppose the value of $\dot{w}_{\mathrm{s}}=\dot{w}_{\mathrm{a}}$ is known, then Equations (6.3) and (6.7) give, at $x=0$,

$$
\sigma_{0 x}(-h)=3.68 \lambda^{2 / 3} A^{-1 / 3} h^{1 / 3} \dot{w}_{\mathrm{s}}^{1 / 3}
$$

However $A=A$ ( $\rho_{\mathrm{i}}$, temperature, salinity, etc.) is not well known, therefore rewriting Equation (6.8) in terms of strain-rate,

$$
\dot{\epsilon}_{0} x(-h)=5^{0} \lambda^{2} h \dot{w}_{\mathrm{s}} .
$$

By using a sensitive strain measuring device such as a network of electro-tapes installed at the estimated hinge-line position, a value of $\dot{\epsilon}_{0 x}(-h)$ might be found, bearing in mind that this value will actually be the change in strain-rate at this point over the appropriate time interval. This is because of the horizontal steady-state creep of the slab (Weertman, 1957). The measured value could then be compared with the calculated value in order to test the theory. 
Taking a typical value of $\dot{w}_{\mathrm{a}}=\dot{w}_{\mathrm{s}} \approx 2.3 \times 10^{-5} \mathrm{~m} \mathrm{~s}^{-1}$ for the Ross Sea, $\dot{\epsilon}_{0} x(-h) \approx \mathrm{I}_{1} 4 \times \mathrm{IO}^{-7} \mathrm{~s}^{-1}$, which is well above the general range for fracturing of ice (Holdsworth, I965); therefore at least a tide crack should form, and indeed these are generally visible.

\section{Discussion}

Before being able to predict any failure criterion, it is necessary to have a knowledge of the bending strength of ice. Tabata (1967, p. 486) indicates that at stress rates below 0.1 bar s ${ }^{-1}$ the bending strength increases with decreasing stress rate, but the data are not extended to the stress rates generally dealt with in the present analysis. Although Tabata's values for the bending strength cannot be used directly here, because a different type of ice was used, it is expected that the same order of bending strengths (9-13 bar) would probably apply in the present case. Additional information comes from tables in Mantis (I95I) which indicate values of the bending strength of unspecified ice as being up to $244 \mathrm{lb} \mathrm{in}^{-2}$ ( $17.5 \mathrm{bar}$ ). These miscellaneous model tests suffer from the well-known "notch effect"bending strength of polar glacier ice is at least as great as 15 bar and probably greater, because if the elastic analysis is valid, ice tongues such as the Erebus Glacier Tongue must have passed through the critical length $5 \pi / 4 \lambda$ without breaking off completely under I5 bar tension.

The map of Antarctica (e.g. that published by the American Geographical Society, I : $5000 \mathrm{ooo}$, in 1965) discloses the fact that in the Weddell Sea, ice tongues of the type found in the Ross Sea are not found. A reason for this may be provided by the tidal data which show (Thiel and others, 1960) a tidal range in the Weddell Sea about three times greater than the Ross Sea. Consequently hinge bending stresses in a similar slab there would be three times as great as in the latter place, so total failure might be expected.

The present discussion has dealt with tidally induced stresses with half periods from 6 to I $2 \mathrm{~h}$ (Weddell and Ross Seas respectively). Oscillations of the slab due to wave action (or swell) with half periods of less than $30 \mathrm{~s}$ should place the system within the limits of elastic theory. However, estimated deflections are generally small. It is quite possible, nevertheless, that violent storms may induce swells of sufficiently large amplitude to generate stresses at the hinge line of the magnitude of tidally produced ones. Moreover these stresses may be generated by moments about the $z$-as well as the $y$-axis, depending on the direction of the swell.

\section{ACKNOWLEDGEMENTS}

The author is indebted to Dr C. Bull for helpful suggestions and to Dr T. Hughes and Dr J. Weertman for making corrections to parts of the manuscript.

This work was supported by grants GA-205 and GA-532 from the National Science Foundation to the Ohio State University Research Foundation.

MS. received 6 May 1968 and in revised form 25 February 1969

\section{REFERENCES}

Dorsey, N. E. 1940. Properties of ordinary water-substance in all its phases: water-vapor, water and all the ices. New York, Reinhold Publishing Corporation. (American Chemical Society. Monograph Series, No. 8r.)

Glen, J. W. 1955. The creep of polycrystalline ice. Proceedings of the Royal Society, Ser. A, Vol. 228, No. 1175 , p. $5^{1} 9^{-3} 8$.

Hetényi, M. 1946. Beams on elastic foundation. Ann Arbor, University of Michigan Press.

Holdsworth, G. 1965. An examination and analysis of the formation of transverse crevasses, Kaskawulsh Glacier, Yukon Territory, Canada. Ohio State University. Institute of Polar Studies. Report No. 16.

Mantis, H. T., ed. 1951. Review of the properties of snow and ice. U.S. Snow, Ice and Permafrost Research Establishment. Report 4. 
Nye, J. F. 1951. The flow of glaciers and ice-sheets as a problem in plasticity. Proceedings of the Royal Society, Ser. A, Vol. 207, No. 109i, p. 554-72.

Prager, W., and Hodge, P. G. I951. Theory of perfectly plastic solids. New York, John Wiley and Sons, Inc. (Applied Mathematics Series.)

Reeh, N. 1968. On the calving of ice from floating glaciers and ice shelves. Fournal of Glaciology, Vol. 7, No. 50, p. $215^{-32 .}$

Stewart, H. B. [1963.] The global sea. Princeton, N. J., etc.: Van Nostrand. (Searchlight Books.)

Tabata, T. 1967. Flexural strength of small sea ice beams. (In Oura, H., ed. Physics of snow and ice: international conference on low temperature science. ... 1966. . . Proceedings, Vol. I, Pt. I. [Sapporo], Institute of Low Temperature Science, Hokkaido University, p. $48 \mathrm{I}-97$.)

Thiel, E., and Ostenso, N. A. 1961. The contact of the Ross Ice Shelf with the continental ice sheet, Antarctica. Fournal of Glaciology, Vol. 3, No. 29, p. 823-32.

Thiel, E., and others. 1960. Gravimetric determination of ocean tide, Weddell and Ross Seas, Antarctica, by E. Thiel, A. P. Crary, R. A. Haubrich and J. C. Behrendt. Journal of Geophysical Research, Vol. 65, No. 2 , p. $629-36$.

Weertman, J. 1957. Deformation of floating ice shelves. Fournal of Glaciology, Vol. 3, No. 21, p. $3^{8-42 .}$

Weinman, J. A. 1958. Ice shelf oscillations. Fournal of Glaciology, Vol. 3, No. 23, p. 187.

Wilson, A. T. 1964. Origin of ice ages: an ice shelf theory for Pleistocene glaciation. Nature, Vol. 201, No. 49 I 5 p. $147-49$. 